OPEN ACCESS

Edited by:

Louise Lafortune,

University of Cambridge,

United Kingdom

Reviewed by:

Alexjandro C. Daviano,

EBSCO Health, United States

Fiona Alpass,

Massey University, New Zealand

*Correspondence:

Daniel Juárez Santos-García daniel.juarez@uclm.es

Specialty section: This article was submitted to Aging and Public Health,

a section of the journal

Frontiers in Public Health

Received: 12 December 2019

Accepted: 31 March 2020

Published: 12 May 2020

Citation:

González-Ravé JM, Cuéllar-Cañadilla R, García-Pastor T and Juárez Santos-García D (2020) Strength Improvements of Different 10-Week Multicomponent Exercise

Programs in Elderly Women.

Front. Public Health 8:130.

doi: 10.3389/fpubh.2020.00130

\section{Strength Improvements of Different 10-Week Multicomponent Exercise Programs in Elderly Women}

\author{
José María González-Ravé ${ }^{1}$, Rubén Cuéllar-Cañadilla ${ }^{1}$, Teresa García-Pastor ${ }^{2}$ and \\ Daniel Juárez Santos-García ${ }^{1 *}$ \\ ${ }^{1}$ Department of Physical Activity and Sport Sciences, University of Castilla la Mancha, Toledo, Spain, ${ }^{2}$ Department of Sport \\ Sciences, University of Camilo Jose Cela, Madrid, Spain
}

The purpose of this study was to analyze and compare the effects of various muscle strength sessions performed during 10 weeks physical conditioning programs and 4 weeks of detraining on the physical conditioning, body composition and hematology of elderly women. 48 women were randomly distributed in four groups: a physical conditioning group (PCG; $n=12$ ) with two sessions per week; a PCG with an extra-session focus on hypertrophy (PCGH; $n=12$ ), a PCG with an extra-session in a shallow pool (PCGP; $n=12$ ); and a control group (CG; $n=12$ ). PCGH achieved a significant increase in Abalakov. Significant differences between the CG and the other groups were found in Countermovement Jump. There were significant improvements in the chair-stand test in the PCG and PCGH. The training programs suspected improvements in HDL, LDL, baseline glucose and glycated hemoglobin. In conclusion, a training program with an extra-session focus on hypertrophy achieved a greater improvement in strength in elderly women.

Keywords: strength, training, female, physical programs, jumps

\section{INTRODUCTION}

The physiological and anatomical characteristics of elderly adults deteriorate over the years. Their functional capacity decreases and changes occur at the respiratory, cardiovascular, renal, nervous and muscle-skeletal level (1). In women, especially after menopause, various physical abilities (strength, flexibility, equilibrium, resistance, and agility) follow a natural evolution of loss with age (2).

Over the last 10 years, there have been numerous and varied physical conditioning programs aimed at adults older than 60 years. These programs have sought to improve physical characteristics and body composition, optimizing and improving the quality of life of these individuals (3-6).

One of the most common programs that has proliferated it's self in social/cultural centers and in municipal sports programs is the general physical conditioning or multicomponent program This sort of exercise plan has had positive effects on the health in women older than 60 years $(6,7)$.

However, most scientific literature has focused on strength training in elderly adults. Most studies that are focused on increasing the muscle strength and functional strength of elderly adults using hypertrophy or neural adaptation methods were implemented in a period varying between 6 and 16 weeks, with a weekly frequency of two to three sessions, obtaining strength gains in upper and lower limbs (8-13). 
Additionally, all of these programs caused changes, which if not performed periodically can lead to losses in strength, functional performance and body composition after the end of the training periods $(12,14)$. The clinical relevance of the neuromuscular adaptations induced by strength training is its impact on the daily living activities, especially when the strength training performed for several weeks led to greater improvements in strength in the arms and legs.

Therefore, Considering the importance of physical exercise in women older than 60 years, particularly strength training, it is essential to continue analyzing different physical conditioning programs in order to determine the best protocols for improving physical fitness in this population.

The aim of this study was to analyze and compare the effects of various muscle strength sessions implemented in 10-week physical conditioning programs, with a 4 weeks detraining, on the physical conditioning, body composition and hematology of elderly women.

\section{MATERIALS AND METHODS}

\section{Design}

In an interventional controlled trial, a general conditioning program alone, the same program with a focus on hypertrophy, or the same program with an extra pool session was used to analyze the effects of different training sessions and deconditioning after completing the program in elderly women. The program implemented lasted 10 weeks, followed by a 4 weeks detraining period.

\section{Subjects}

Forty-eight women (mean age, 65.7, $s=4.5$ years; mean weight, $75.3, s=11.1 \mathrm{~kg}$ ) voluntarily participated in this study. The sample size was calculated by estimating a large effect size, $\alpha$ of 0.05 , and power of 0.8 . The sample was divided into four groups and four measurement moments were established (pre-post 1 (after the training program), post 2 and post 3 (two and 4 weeks after finishing the training program). Participants had performed in 3-5 years of controlled physical exercise.

Participants were randomly selected from people involved in the senior activity program of the Community Center of Madridejos (Toledo, Spain). All tests and training programs were carried out at the Sport city center which belongs to the Municipality of Madridejos. The participants were assessed between February and June of 2016. They were checked thoroughly during all medical procedures by medical staff (doctor and nurse). To be included in the study participants had to be aged 60 and 80 years old, and live within $50 \mathrm{~km}$ of a metropolitan area.

The inclusion criteria were the following: women between the ages of 60 and 80 years participating for more than 3 years in elderly physical exercise programs in the Municipality of Madridejos (Toledo, Spain) The exclusion criteria were a history of cardiac, respiratory or joint movement problems, problems with dizziness during exertion, propensity for infections, use of drugs that could endanger the participant during the implementation of the program and participation in a physical conditioning program aimed at developing strength in the past 6 months.

A parallel group design was performed. The participants were randomly distributed to four groups: a general physical conditioning group (PCG; $n=12$ ), a general physical conditioning group with hypertrophy development (PCGH; $n$ $=12$ ), a general physical conditioning group with strength development in a swimming pool (PCGP; $n=12$ ) and a control group (CG; $n=12$ ).

The participants were informed of the benefits and risks prior to signing the informed consent document to participate in the research. The study was approved by the Clinical Research Ethics Committee of the University of Castilla-La Mancha and conducted in accordance with the Helsinki Declaration.

\section{Procedures}

\section{Training Program}

The training programs were conducted for 10 weeks from February to April, 2016. Previously, all groups had performed two familiarization sessions with the assessment tests, and the training groups were also familiarized with the exercises to be performed. All study groups had several training elements in common (Table 1). The participants were asked not to participate in other physical activities during the study period.

The training was differentiated as follows:

- PCG: performed the previous program exclusively.

- PCGH: the extra session performed per week can be seen in (Table 2). In the familiarization sessions, we determined the work intensity, calculating the 12 repetition maximum (RM) of the exercises to be performed during the program (except in the abdominal and dorsal-lumbar extension exercises). We used variable resistance machines. Work was performed with the following exercise circuit, according to (Table 2).

- Circuit 1: 1-Leg extension in pulley. 2- Rectus abdominis (Extended leg crunch) (25 reps). 3- Low pulley row. 4- Abductors seated on machine (Gluteus maximus). 5Dorsal-lumbar extension in lying prone position (25 reps). 6- Alternating biceps curl with supination (seated). 7Lifting the heels in the machine. 8- Alternating frontal liftings with low pulley.

- Circuit 2: 1- Leg curl lying down (hamstrings). 2- Oblique abdominals (25 reps). 3 - Bench press in machine (Pectoralis major). 4- Abductors seated on machine. 5- Triceps extension in high pulley. 6- Unilateral dorsal-lumbar extension in lying prone position (25 reps). 7- Leg press inclined. 8. Pulldown with pulley to chest.

- Circuit 3: 1-Pull over with high pulley (latissimus dorsi). 2- Semi-squat in multipower. 3- Anterior deltoids in machine (shoulder press). 4- Gluteus medius (hip abduction standing in machine). 5- Abdominal crunches with legs (25 reps). 6- Butterfly chest contractions. 7- Unilateral dorsallumbar extension in lying prone position (25 reps). 8Lateral lunges with dumbbells.

- PCGP: performed a training similar to that of the previous group in terms of muscles involved but different in terms of 
TABLE 1 | Exercise program performed by training groups.

\begin{tabular}{|c|c|c|c|}
\hline Frequency & Intensity & Time & Type \\
\hline Once a week. & $\begin{array}{l}\text { 60-70\% Estimated heart rate (HR), combined with } 70-80 \% \\
\text { (speech test). }\end{array}$ & $40 \mathrm{~min}$ & $\begin{array}{l}\text { Mean aerobic (cardiovascular exercises with } \\
\text { musical base) combined with intermittent } \\
\text { exertions. }\end{array}$ \\
\hline Once a week. & $\begin{array}{l}60-70 \% 1 \mathrm{RM} \text {; Character of exertion (12-15 of } 20 \text { repetitions) with } \\
\text { moderate execution speed. }\end{array}$ & $\begin{array}{l}8-10 \text { exercises } \times 3 \times \\
12-15 / 30 "\end{array}$ & $\begin{array}{l}\text { Strength-resistance (use of auxiliary material } \\
\text { and calisthenics with the body itself. }\end{array}$ \\
\hline Twice a week. & $\begin{array}{l}\text { Joint range of movement (ROM) (Progressive reach of the } \\
\text { maximum). }\end{array}$ & $\begin{array}{l}(5 \text { exercises } \times 1-3 \times 20 " / 10 ") / \\
\text { session }\end{array}$ & Flexibility (Joint ROM improvement). Stretching. \\
\hline Once a week. & $\begin{array}{l}\text { Progression in the difficulty level (no. of supports, equilibrium base, } \\
\text { distribution of supports). }\end{array}$ & 5 exercises $\times 2$ '/30" & Static and dynamic equilibrium. \\
\hline Once a week. & $\begin{array}{l}\text { Progression in the difficulty level (from hand-eye coordination to } \\
\text { foot-eye coordination; from intraindividual to interindividual } \\
\text { coordination; stable environments to unstable environments). }\end{array}$ & 3 exercises $\times 33^{\prime} / 30 "$ & Coordination and agility. \\
\hline
\end{tabular}

TABLE 2 | Programming of the specific training group with an extra strength session (PCGH).

\begin{tabular}{|c|c|c|c|}
\hline Week & Volume & Intensity & Exercises \\
\hline 1 & 8 exercises $\times\left(2 \times 12 / 1^{\prime}\right) / 3^{\prime}$ & - $70 \% 1 \mathrm{RM}$ & CIRCUIT 1 \\
\hline 2 & 8 exercises $\times\left(2 \times 12 / 1^{\prime}\right) / 3^{\prime}$ & - $70 \% 1 \mathrm{RM}$ & CIRCUIT 2 \\
\hline 3 & 8 exercises $\times\left(2 \times 12 / 1^{\prime}\right) / 3^{\prime}$ & - $70 \% 1 \mathrm{RM}$ & CIRCUIT 3 \\
\hline 4 & 8 exercises $\times\left(3 \times 12 / 1^{\prime}\right) / 3^{\prime}$ & - $70 \% 1 \mathrm{RM}$ & CIRCUIT 1 \\
\hline 5 & 8 exercises $\times\left(3 \times 12 / 1^{\prime}\right) / 3^{\prime}$ & - $70 \% 1 \mathrm{RM}$ & CIRCUIT 2 \\
\hline 6 & 8 exercises $\times\left(3 \times 12 / 1^{\prime}\right) / 3^{\prime}$ & - $70 \% 1 \mathrm{RM}$ & CIRCUIT 3 \\
\hline 7 & 8 exercises $\times\left(3 \times 8 / 2^{\prime}\right) / 3^{\prime}$ & - $80 \% 1 \mathrm{RM}$ & CIRCUIT 1 \\
\hline 8 & 8 exercises $\times\left(3 \times 8 / 2^{\prime}\right) / 3^{\prime}$ & - $80 \% 1 \mathrm{RM}$ & CIRCUIT 2 \\
\hline 9 & 8 exercises $\times\left(3 \times 8 / 1^{\prime} 30 "\right) / 3^{\prime}$ & - $80 \% 1 \mathrm{RM}$ & CIRCUIT 3 \\
\hline 10 & 8 exercises $\times\left(3 \times 8 / 1^{\prime} 30 "\right) / 3^{\prime}$ & - $80 \% 1 \mathrm{RM}$ & CIRCUIT 1 \\
\hline
\end{tabular}

$1 R M, 1$ repetition maximum.

intensity and speed of execution (Table 3). This session was performed in a heated swimming pool and with the use of various auxiliary materials (boards, pull-buoys, pool noodles, and paddles). A musical base was employed to increase the participants' motivation.

The exercise circuits performed were as follows:

Circuit 1

1- Jumping Jack (opening and closing of the legs) with extension/flexion of the elbow. 2- Rectus abdominis ( $\mathrm{V}$ with legs bent). 3- Traction with board in the water. 4- Knee extensions with lateral inclination (Lateral kicking). 5- Ventral to dorsal flotation. 6- Bicep supination with paddles. 7- Multiple tip-toe hops. 8- Shoulder adduction with pull-buoys.

Circuit 2

1- Femoral (heel to buttock). 2- Oblique abdominals (unilateral inclination with elbow extension). 3- Pushing with boards. 4- Pendulum to 1 leg with pool noodle (hip adduction). 5Elbow extensions with paddles. 6- Ventral to dorsal flotation. 7Alternating knee extension (in suspension). 8- Frontal shoulder adduction with pull-buoys.

Circuit 3
TABLE 3 | Factors for the programming of the specific block in the PCGP training group.

\begin{tabular}{|c|c|c|c|}
\hline Week & Volume & Intensity & Exercises \\
\hline 1 & $\begin{array}{l}8 \text { exercises } \times(2 \times 20 / 30 ") / 2^{\prime} \\
\text { (active rest). }\end{array}$ & $\begin{array}{l}\text { - RPE (Borg): } 7 \\
\text { - Bpm: } 120\end{array}$ & CIRCUIT 1 \\
\hline 2 & $\begin{array}{l}8 \text { exercises } \times(2 \times 20 / 30 ") / 2 \\
\text { (active rest). }\end{array}$ & $\begin{array}{l}\text { - RPE (Borg): } 7 \\
\text { - Bpm: } 120\end{array}$ & CIRCUIT 2 \\
\hline 3 & $\begin{array}{l}8 \text { exercises } \times(2 \times 20 / 30 ") / 2 \\
\text { (active rest). }\end{array}$ & $\begin{array}{l}\text { - RPE (Borg): } 7 \\
\text { - Bpm: } 120\end{array}$ & CIRCUIT 3 \\
\hline 4 & $\begin{array}{l}8 \text { exercises } \times(3 \times 20 / 30 ") / 2 \\
\text { (active rest). }\end{array}$ & $\begin{array}{l}\text { - RPE (Borg): } 7 \\
\text { - Bpm: } 120\end{array}$ & CIRCUIT 1 \\
\hline 5 & $\begin{array}{l}8 \text { exercises } \times(3 \times 20 / 30 ") / 2^{\prime} \\
\text { (active rest). }\end{array}$ & $\begin{array}{l}\text { - RPE (Borg): } 7 \\
\text { - Bpm: } 120\end{array}$ & CIRCUIT 2 \\
\hline 6 & $\begin{array}{l}8 \text { exercises } \times(3 \times 20 / 30 ") / 2 \\
\text { (active rest). }\end{array}$ & $\begin{array}{l}\text { - RPE (Borg): } 7 \\
\text { - Bpm: } 120\end{array}$ & CIRCUIT 3 \\
\hline 7 & $\begin{array}{l}8 \text { exercises } \times(3 \times 20 / 30 ") / 2^{\prime} \\
\text { (active rest). }\end{array}$ & $\begin{array}{l}\text { - RPE (Borg): } 8 \\
\text { - Bpm: } 130\end{array}$ & CIRCUIT 1 \\
\hline 8 & $\begin{array}{l}8 \text { exercises } \times(3 \times 20 / 30 ") / 2 \\
\text { (active rest). }\end{array}$ & $\begin{array}{l}\text { - RPE (Borg): } 8 \\
\text { - Bpm: } 130\end{array}$ & CIRCUIT 2 \\
\hline 9 & $\begin{array}{l}8 \text { exercises } \times(3 \times 20 / 30 ") / 2 \text { ' } \\
\text { (active rest). }\end{array}$ & $\begin{array}{l}\text { - RPE (Borg): } 8 \\
\text { - Bpm: } 130\end{array}$ & CIRCUIT 3 \\
\hline 10 & $\begin{array}{l}8 \text { exercises } \times(3 \times 20 / 30 ") / 2 \\
\text { (active rest). }\end{array}$ & $\begin{array}{l}\text { - RPE (Borg): } 8 \\
\text { - Bpm: } 130\end{array}$ & CIRCUIT 1 \\
\hline
\end{tabular}

Bpm, beats per minute; RPE, Rating of Perceived Exertion.

1- Tractions with pull-buoys. 2- Hops with semi-squat. 3Deltoids with board (vertical elbow extension). 4- Hip extensions. 5- Rectus abdominis. 6- Unilateral push with elbow extension and with pull-buoys. 7- Lateral turns using the elbows in flexion. 8- Lateral lunge with elbow extension and board facing forward.

After completing the training programs (POST1), the assessment tests were repeated 2 (POST2) and 4 (POST3) weeks later (except for the blood analysis, which was performed only once [POST1] after the intervention).

\section{Testing procedures}

Prior to applying the training programs, the following measurements were performed, scheduling each group on a different day: 
- Blood analysis, recording the cholesterol (total, HDL and $\mathrm{LDL}$ ), hemoglobin ( $\mathrm{Hb}), \mathrm{HB}$ (HbAlc), hematocrit (HCT) and glucose.

- Body composition analysis through bioimpedance (Inbody 230, Biospace Co. Ltd., Seoul, South Korea).

- Countermovement jump test (CMJ) and Abalakov (ABK) using the Optojump contact barriers (Microgate, Italy), performing two attempts of each jump, separated by $2 \mathrm{~min}$, and selecting the highest jump.

- Test for standing and sitting in a chair the highest number of times possible in $30 \mathrm{~s}$. This test is part of the battery of tests known as the Senior Fitness Test (STF) (15). The test consists of sitting down and standing up as many times as possible in $30 \mathrm{~s}$, without using the hands. This test was performed using a chair without armrests, with a height of $40 \mathrm{~cm}$. The chair was placed against a wall to prevent it from moving during the implementation of the test. The test began with the individual seated in the chair, with the back straight and supported on the backrest, the feet parallel and placed on the floor in a straight line with the knees to maintain balance during the test. The arms are crossed at the chest.

- Biceps curl test with $2.5 \mathrm{~kg}$ for $30 \mathrm{~s} \mathrm{(15).} \mathrm{To} \mathrm{start} \mathrm{the} \mathrm{test,} \mathrm{the}$ individual must sit down in a chair without armrests with the back straight and the feet completely placed on the floor. The participants took the dumbbell with their dominant hand and placed it perpendicular to the floor, with their elbow against the body and the palm of the hand upwards. The participants lifted the dumbbell to the shoulder and then returned it to the starting position, performing as many repetitions as possible within $30 \mathrm{~s}$.

- The 6-min walking test covering the longest distance possible, covering a rectangular circuit $(29 \times 0.5 \mathrm{~m})$. The short walking test has been shown to correlate well with cardiopulmonary resistance in elderly adults with differing health conditions $(16,17)$.

\section{Statistical Analyses}

The SPSS v.22 program was employed for the data analysis. The normality of the variables was analyzed with the ShapiroWilk test. Homoscedasticity was checked with Levene's test. To analyze the differences between groups for each of the variables, we applied an ANOVA of repeated measures (group $\times$ moment) with a Bonferroni post hoc test. Statistical significance was established at $p<0.05$. We calculated the size of the effect using the partial eta squared $\left(\eta^{2}\right)$ in the ANOVA analysis and through Cohen's $\mathrm{d}$ in the comparisons by pairs.

\section{RESULTS}

The results of all parameters are showed in (Tables 4-11). There were no significant differences in the changes between the groups or between the various assessments performed for the body weight, body fat percentage and muscle mass variables.

In terms of the variables obtained with the blood tests, we saw differences between the resulting changes between the groups. In the cholesterol-related variables, these differences were primarily observed in total cholesterol $(p=0.02 ; \eta=0.2)$, mainly by
TABLE 4 | Results of Abalakov jump (cm) test (mean \pm SD).

\begin{tabular}{lcccc}
\hline & $\begin{array}{c}\text { CG } \\
(\boldsymbol{n}=\mathbf{1 2})\end{array}$ & $\begin{array}{c}\text { PCG } \\
(\boldsymbol{n}=\mathbf{1 2})\end{array}$ & $\begin{array}{c}\text { PCGH } \\
(\boldsymbol{n}=\mathbf{1 2})\end{array}$ & $\begin{array}{c}\text { PCGP } \\
(\boldsymbol{n}=\mathbf{1 2})\end{array}$ \\
\hline Pre-training & $6.71 \pm 3.73$ & $10.18 \pm 3.99$ & $8.53 \pm 1.93$ & $7.17 \pm 3.25$ \\
Post-training1 & $7.22 \pm 3.88$ & $10.68 \pm 3.23$ & $10.20 \pm 2.39^{\star \star}$ & $7.87 \pm 2.77$ \\
Post-training2 & $6.05 \pm 3.19$ & $9.97 \pm 3.54$ & $10.83 \pm 3.34^{\star \star}$ & $8.42 \pm 2.79$ \\
Post-training3 & $6.55 \pm 3.46$ & $9.78 \pm 3.75$ & $10.15 \pm 3.25^{\star \star}$ & $8.07 \pm 3.03$
\end{tabular}

**Difference $(p<0.01)$ with pre-training.

TABLE 5 | Results of CMJ (cm) test (mean \pm SD).

\begin{tabular}{lcccc}
\hline & $\begin{array}{c}\text { CG } \\
(\boldsymbol{n}=\mathbf{1 2})\end{array}$ & $\begin{array}{c}\text { PCG } \\
(\boldsymbol{n}=\mathbf{1 2})\end{array}$ & $\begin{array}{c}\text { PCGH } \\
(\boldsymbol{n}=\mathbf{1 2})\end{array}$ & $\begin{array}{c}\text { PCGP } \\
(\boldsymbol{n}=\mathbf{1 2})\end{array}$ \\
\hline Pre-training & $6.51 \pm 3.03$ & $8.76 \pm 2.86$ & $8.08 \pm 1.91$ & $6.16 \pm 2.57$ \\
Post-training1 & $5.61 \pm 2.87$ & $9.17 \pm 3.34^{\#}$ & $8.85 \pm 1.66$ & $7.07 \pm 2.82$ \\
Post-training2 & $5.49 \pm 2.83$ & $9.18 \pm 3.38^{\#}$ & $9.87 \pm 2.15^{\# \# \star * \&}$ & $7.29 \pm 2.29^{\star}$ \\
Post-training3 & $5.87 \pm 3.02$ & $9.38 \pm 2.89^{\#}$ & $9.51 \pm 2.56^{\# \star}$ & $7.47 \pm 2.15^{\star}$ \\
\hline
\end{tabular}

\#Difference $(p<0.05)$ with CG.

\#\# Difference $(p<0.01)$ with CG.

${ }^{*}$ Difference $(p<0.05)$ with pre-training.

${ }^{*}$ Difference $(p<0.01)$ with pre-training

\& Difference $(p<0.05)$ with post-training1.

TABLE 6 | Results of Biceps curl in $30 \mathrm{~s}$ (repetitions) test (mean \pm SD).

\begin{tabular}{lcccc}
\hline & $\begin{array}{c}\text { CG } \\
(\boldsymbol{n}=\mathbf{1 2})\end{array}$ & $\begin{array}{c}\text { PCG } \\
(\boldsymbol{n}=\mathbf{1 2})\end{array}$ & $\begin{array}{c}\text { PCGH } \\
(\boldsymbol{n}=\mathbf{1 2})\end{array}$ & $\begin{array}{c}\text { PCGP } \\
(\boldsymbol{n}=\mathbf{1 2})\end{array}$ \\
\hline Pre-training & $10.37 \pm 3.25$ & $13.92 \pm 2.60$ & $13.25 \pm 3.05$ & $12.17 \pm 2.92$ \\
Post-training1 & $12.62 \pm 3.70$ & $15.77 \pm 2.59$ & $16.17 \pm 1.75^{\star \star}$ & $14.25 \pm 3.05^{\star}$ \\
Post-training2 & $14.00 \pm 3.62^{\star \star}$ & $16.23 \pm 2.65^{\star *}$ & $16.58 \pm 1.83^{\star \star}$ & $14.92 \pm 2.43^{\star \star}$ \\
Post-training3 & $14.12 \pm 3.48^{\star \star}$ & $16.92 \pm 2.22^{\star *}$ & $16.25 \pm 1.76^{\star \star}$ & $14.83 \pm 2.25^{\star \star}$
\end{tabular}

${ }^{*}$ Difference $(p<0.05)$ with pre-training.

${ }^{*}$ Difference $(p<0.01)$ with pre-training.

TABLE 7 | Results of Stand Chair (repetitions) test (mean \pm SD).

\begin{tabular}{lcccc}
\hline & $\begin{array}{c}\text { CG } \\
(\boldsymbol{n}=\mathbf{1 2})\end{array}$ & $\begin{array}{c}\text { PCG } \\
(\boldsymbol{n}=\mathbf{1 2})\end{array}$ & $\begin{array}{c}\text { PCGH } \\
(\boldsymbol{n}=\mathbf{1 2})\end{array}$ & $\begin{array}{c}\text { PCGP } \\
(\boldsymbol{n}=\mathbf{1 2})\end{array}$ \\
\hline $\begin{array}{l}\text { Pre- } \\
\text { training }\end{array}$ & $14.00 \pm 1.41$ & $15.85 \pm 2.15$ & $16.33 \pm 1.56$ & $14.25 \pm 2.14$ \\
$\begin{array}{l}\text { Post- } \\
\text { training1 }\end{array}$ & $14.12 \pm 2.85$ & $17.08 \pm 2.36^{\# *}$ & $18.00 \pm 1.71^{\# \# *}$ & $14.67 \pm 2.50^{\# \# \&}$ \\
$\begin{array}{l}\text { Post- } \\
\text { training2 }\end{array}$ & $13.00 \pm 1.93$ & $16.92 \pm 2.22^{\# \#}$ & $17.08 \pm 1.93^{\# \#}$ & $14.75 \pm 2.60$ \\
$\begin{array}{l}\text { Post- } \\
\text { training3 }\end{array}$ & $13.25 \pm 2.05$ & $17.46 \pm 2.96^{\# \# @^{* *}}$ & $17.17 \pm 1.40^{\# \#}$ & $14.33 \pm 2.42$ \\
\hline
\end{tabular}

\# Difference $(p<0.05)$ with CG.

\#\# Difference $(p<0.01)$ with $C G$.

\& Difference $(p<0.01)$ with PCGH.

${ }^{\circledR}$ Difference $(p<0.05)$ with PCGP.

${ }^{*}$ Difference $(p<0.05)$ with pre-training.

${ }^{*}$ Difference $(p<0.01)$ with pre-training. 
TABLE 8 | Results of 6-min walking $(\mathrm{m})$ test (mean \pm SD).

\begin{tabular}{lcccc}
\hline & $\begin{array}{c}\text { CG } \\
(\boldsymbol{n}=\mathbf{1 2})\end{array}$ & $\begin{array}{c}\text { PCG } \\
(\boldsymbol{n}=\mathbf{1 2})\end{array}$ & $\begin{array}{c}\text { PCGH } \\
(\boldsymbol{n}=\mathbf{1 2})\end{array}$ & $\begin{array}{c}\text { PCGP } \\
(\boldsymbol{n}=\mathbf{1 2})\end{array}$ \\
\hline $\begin{array}{l}\text { Pre- } \\
\text { training }\end{array}$ & $474.37 \pm 55.90$ & $533.08 \pm 60.30$ & $501.67 \pm 87.32$ & $484.58 \pm 61.62$ \\
$\begin{array}{l}\text { Post- } \\
\text { training1 }\end{array}$ & $465.62 \pm 65.16$ & $541.92 \pm 28.25$ & $537.92 \pm 33.13$ & $508.33 \pm 38.45$ \\
$\begin{array}{l}\text { Post- } \\
\text { training2 }\end{array}$ & $450.00 \pm 56.38$ & $540.00 \pm 31.22$ & $525.83 \pm 31.83$ & $514.58 \pm 29.88$ \\
$\begin{array}{l}\text { Post- } \\
\text { training3 }\end{array}$ & $468.75 \pm 50.20$ & $541.15 \pm 35.72$ & $525.83 \pm 35.73$ & $513.75 \pm 39.03$ \\
\hline
\end{tabular}

TABLE 9 | Results of body fat (\%) and muscle mass (kg) analysis (mean \pm SD).

\begin{tabular}{llccc}
\hline & \multicolumn{1}{c}{ GC } \\
& \multicolumn{1}{c}{$\boldsymbol{( n = 1 2 )}$} & $\begin{array}{c}\text { PCG } \\
(\boldsymbol{n}=\mathbf{1 2})\end{array}$ & $\begin{array}{c}\text { PCGH } \\
(\boldsymbol{n}=\mathbf{1 2})\end{array}$ & $\begin{array}{c}\text { PCGP } \\
(\boldsymbol{n}=\mathbf{1 2})\end{array}$ \\
\hline Body fat (\%) & & & & \\
Pre-training & $46.44 \pm 7.42$ & $45.09 \pm 4.19$ & $45.82 \pm 4.15$ & $45.49 \pm 3.00$ \\
Post-training1 & $47.47 \pm 7.36$ & $45.02 \pm 4.20$ & $45.97 \pm 4.54$ & $46.02 \pm 3.32$ \\
Post-training2 & $46.85 \pm 6.91$ & $45.12 \pm 3.67$ & $45.52 \pm 4.82$ & $45.70 \pm 3.20$ \\
Post-training3 & $47.34 \pm 7.38$ & $44.48 \pm 4.49$ & $45.68 \pm 4.56$ & $45.59 \pm 3.44$ \\
Muscle mass (Kg) & & & \\
Pre-training & $22.99 \pm 2.76$ & $22.33 \pm 2.87$ & $22.26 \pm 3.22$ & $21.37 \pm 3.05$ \\
Post-training1 & $21.70 \pm 2.60$ & $22.40 \pm 2.69$ & $22.01 \pm 3.17$ & $21.19 \pm 3.56$ \\
Post-training2 & $22.00 \pm 2.82$ & $22.27 \pm 2.52$ & $22.00 \pm 3.11$ & $21.31 \pm 3.21$ \\
Post-training3 & $21.86 \pm 2.45$ & $22.71 \pm 2.98$ & $21.96 \pm 3.35$ & $21.37 \pm 3.08$ \\
\hline
\end{tabular}

TABLE 10 | Results of total cholesterol. LDL and HDL (mg/dl) analysis (mean \pm $\mathrm{SD})$.

\begin{tabular}{cccc}
\hline CG & PCG & PCGH & PCGP \\
$(n=12)$ & $(n=12)$ & $(n=12)$ & $(n=12)$ \\
\hline
\end{tabular}

\section{Total cholesterol (mg/dl)}

$\begin{array}{lrrrr}\begin{array}{l}\text { Pre- } \\ \text { training }\end{array} & 194.25 \pm 22.82 & 201.23 \pm 23.53 & 208.58 \pm 27.63 & 203.00 \pm 22.37 \\ \begin{array}{l}\text { Post- } \\ \text { training1 }\end{array} & 207.25 \pm 11.45^{\star *} & 200.31 \pm 11.87 & 203.25 \pm 25.37 & 202.13 \pm 17.62 \\ \text { LDL (mg/dl) } & & & \\ \begin{array}{l}\text { Pre- } \\ \text { training }\end{array} & 120.49 \pm 25.01 & 117.41 \pm 14.99 & 128.36 \pm 18.92 & 113.94 \pm 13.04 \\ \begin{array}{l}\text { Post- } \\ \text { training1 }\end{array} & 123.19 \pm 17.77 & 114.49 \pm 10.37 & 123.36 \pm 16.83^{\star} & 110.28 \pm 13.32 \\ \text { HDL (mg/dl) } & & & \\ \begin{array}{l}\text { Pre- } \\ \text { training }\end{array} & 56.50 \pm 5.24 & 53.92 \pm 8.20 & 51.75 \pm 5.59 & 54.25 \pm 4.97 \\ \begin{array}{l}\text { Post- } \\ \text { training1 }\end{array} & 58.38 \pm 7.48 & 56.77 \pm 5.57^{*} & 54.33 \pm 4.07 & 56.17 \pm 6.10\end{array}$

${ }^{*}$ Difference $(p<0.05)$ with pre-training.

${ }^{*}$ Difference $(p<0.01)$ with pre-training.

the difference in LDL (n.s.; $\eta=0.1$ ). In the $\mathrm{Hb}$, we mainly saw a difference in the glycated $\mathrm{Hb}(\mathrm{p}=0.005 ; \eta=0.3$; for the $\mathrm{Hb}$ n.s.; $\eta=0.08$ ). There were no significant differences in
TABLE 11 | Results of Hemoglobin (g/dl), Hematocrit (\%), Glucose (mg/dl) and Glycated Hemoglobin (\%) analysis (mean \pm SD).

\begin{tabular}{cccc}
\hline CG & PCG & PCGH & PCGP \\
$(n=12)$ & $(n=12)$ & $(n=12)$ & $(n=12)$
\end{tabular}

\section{Hemoglobin (g/dl)}

$\begin{array}{lllll}\text { Pre-training } & 13.94 \pm 0.81 & 13.97 \pm 0.78 & 13.87 \pm 0.66 & 13.92 \pm 0.67\end{array}$

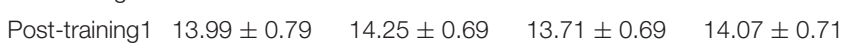

Hematocrit (\%)

$\begin{array}{lllll}\text { Pre-training } & 40.06 \pm 2.90 & 41.00 \pm 3.38 & 40.30 \pm 2.27 & 40.47 \pm 2.39\end{array}$

Post-training1 $39.87 \pm 2.81 \quad 41.28 \pm 2.97 \quad 39.72 \pm 2.47 \quad 41.02 \pm 2.30$

Glucose (mg/dl)

$\begin{array}{lllll}\text { Pre-training } & 97.63 \pm 10.07 & 98.85 \pm 7.64 & 99.08 \pm 9.59 & 102.17 \pm 9.65\end{array}$

Post-training1 $98.88 \pm 12.26 \quad 97.77 \pm 8.68 \quad 91.42 \pm 7.24^{\star *} \quad 99.75 \pm 10.70$

Glycated hemoglobin (\%)

$\begin{array}{lllll}\text { Pre-training } & 5.54 \pm 0.29 & 5.58 \pm 0.32 & 5.61 \pm 0.28 & 5.78 \pm 0.25\end{array}$

Post-training $1 \quad 5.70 \pm 0.29^{*} \quad 5.46 \pm 0.29^{*} \quad 5.47 \pm 0.24^{*} \quad 5.68 \pm 0.35$

${ }^{*}$ Difference $(p<0.05)$ with pre-training.

${ }^{*}$ Difference $(p<0.01)$ with pre-training.

CG, control group; PCG, general physical conditioning group; PCGH, general physical conditioning group (hypertrophy); PCGP, general physical conditioning group (pool).

the hematocrit (n.s.; $\eta=0.06$ ). In terms of glucose, the PCGH showed a significant reduction $(p=0.001 ; d=1.1)$ after the 10 weeks of training.

The results of the jump height in $\mathrm{ABK}$ showed no significant differences among groups or when analyzing only the 10 weeks of training or when considering the entire study period. However, we observed that the PCGH achieved an increase $(p<0.01$, $d=0.7)$ with the training program, without changes among Post training 1, 2, and 3, although these changes are not significant (ns; $d=0.2$ ), the values are still greater than the PRE value $(p<0.01, d=0.7$, for the PRE-POST2 difference, $d$ $=0.5$, for the PRE-POST3 difference). Therefore, no significant differences between-group were found on the ABK measure, but there was a significant within-group difference in the PCGH group.

The results of the ANOVA showed that there were differences $(p<0.01 ; \eta=0.20)$ in the changes produced among all the groups in jump height in CMJ, although these differences were not observed right after the completion of the program but rather subsequently. Differences were found between the CG and the other groups $(p<0.01 ; \eta=0.61$, with the PCGH; $p<0.01 ; \eta=$ 0.25 , with the PCGP; $p<0.05 ; \eta=0.12$, with the PCG). Both the PCGH and PCGP obtained higher values in POST2 and POST3 compared with the PRE value $(p<0.01 ; d=0.8, d=0.5$, in the PCGH between PRE and POST2 and between PRE and POST3, respectively; $p<0.01 ; d=0.5, d=0.6$, in the PCGP between PRE and POST2 and between PRE and POST3, respectively).

In the number of repetitions in biceps curl within $30 \mathrm{~s}$, no significant differences were found in the changes between groups.

Although we did not find significant differences in the changes experienced in the chair standing repetitions between the groups, both the PCG $(p<0.01, d=0.5)$ and PCGH $(p<0.01, d=1)$ showed an increase after the training program. 
Similarly, we found no significant differences, either after the 10 weeks of training or in the entire study period, between the groups in the distance traveled in the 6-minute walking test, although the 3 training groups increased their distance while the control group decreased their distance. The most relevant increase was that of the PCGH $(d=1.1)$ followed by the PCGP $(d=0.6)$.

\section{DISCUSSION}

The aim of this study was to analyze and compare the effects of various muscle strength sessions implemented in 10-week physical conditioning programs and 4 weeks of detraining on the physical condition, body composition and hematology of elderly women. Recent studies have shown that elderly women improved their physical fitness following multicomponent exercise $(6,7)$. Toto et al. (6) analyzed the effects of a 10week multicomponent program and they observed a improving physical performance and activities of daily living. Kang et al. (7) affirmed that multicomponent training programs that consist of "balance, strengthening, and stretching exercises are a relevant intervention for the improvement of the level of physical fitness of older women."

No significant differences between programs were found in body composition. A possible explanation for these results is the fact that although a number of the subjects had some significant improvements in physical fitness, they did not decrease fat mass. This fact suggests that changes in body composition should not be the only indicator of the benefits of exercise in overweight postmenopausal women, as shown by Myette-Côté et al. (18) in their study. Halverstadt et al. (19) found no changes in body composition after 24 weeks of endurance exercise training. In addition, Amarante et al. (20) suggested that a 12-week resistance-training program (3 times a week) improved muscle strength without changes in body composition in elderly women under dietary intake maintenance.

Differences between the groups were found in some of the blood parameters after 10 weeks of the training program, which agrees with Ribeiro et al. (21). Halverstadt et al. (19) observed improvements in plasma lipoprotein and lipid profile with independence of diet and baseline levels after 24 weeks of endurance exercise training. Tomeleri et al. (22) performed a resistance training program consisting of 8 whole-body exercises for 3 sets of 10-15 repetition maximum (RM) performed three times per week with obese elderly women. The program improved inflammatory levels and the lipid and glycemic profiles. Our results agree with those of Martins et al. (23) who concluded that "training programs produced significant benefits in metabolic health indicators of sedentary elderly women and men."

There were no significant differences between the groups after 10 weeks of the physical conditioning program and 4 weeks of detraining in the jump height in ABK. However, the PCGH achieved an increase $(p<0.01, d=0.7)$ between PRETEST and POST1 and between POST1 and POST2. After 4 weeks of training, a significant reduction was produced in POST3. These results agree with those of Delshad et al. (9) who found decreases after 4 weeks of detraining in 50-year-old women. According to the American College of Sports Medicine reports, "strength training is important for improving quality of life and physical function in older adults." Raj et al. (24) obtained improvements in the jump with a strength training program at $75 \%$ of $1 \mathrm{RM}$ for 16 weeks of training in older adults. The results of this study also agree with those of González-Ravé et al. (25) who observed improvements in the vertical jump after 16 weeks of strength training in elderly adults. The results of the CMJ confirm how significant improvements were produced in the jump in the PCGH and PCGP between PRETEST and POST2. Differences were also observed between the experimental groups and the control group.

In terms of performance in muscle resistance in the arms and legs, there were no differences in the 30-s biceps curl test between the groups after the training, although the experimental groups showed improvements on the number of repetitions with the various training programs. Amarante et al. (20) obtained similar results after a 12-week resistance-training program (3 times a week) in improving arm muscle strength, without altering the body composition in elderly women. Similar results were found by Daly et al. (8) after arm strength training for 6 weeks. The chair stand results in this study showed significant improvements in the PCG and PCGH. Jones et al. (26) concluded that the 30-s chair stand test was a good indicator of lower body strength in active older adults. Similar results were found by Taguchi et al. (5) but in elderly adults with a mean age of 84 years.

Finally, although the improvements observed in the 6-min walking test were not significant, the groups who performed the training improved their distance traveled in this test. The improvements in cardiovascular resistance in this type of individual can be greater than those observed in this study, given that in our study $40 \mathrm{~min}$ a week were dedicated specifically to improving the cardiovascular system, an amount of exercise lower than that recommended by the American College of Sport Medicine (27). This can be observed in other studies, such as the one by Hallage et al. (28), where weekly exercise of more than 150 min aimed at cardiovascular resistance was performed. The study obtained significant improvements after 12 weeks of training, although these improvements decreased significantly after 1 month of detraining.

Finally, the main finding of our study was that physically active older women, at least within in the PCGH, improved their muscle power, endurance and local muscular endurance without improvements in body composition and blood tests.

A particular strength of our study lies in the possibility to compare different conditioning programs for elderly women and the follow-up period that allowed us to measure the maintenance of the changes after the training sessions. However, several limitations should be taken into consideration. The small sample size of the study, specifically the control group with fewer participants than the other groups, or the lack of randomization of the sample did not allow us to show more significant results.

In accordance with González-Ravé et al. (25), any training proposal required to put on special attention and individual experimentation in elderly people. A well-planned 
multicomponent training program does not entail an additional overload in the development of skeletal muscle in elderly women, as evidenced by an adaptive response without acute fatigue or overtraining, and by biochemical parameters. This is an important finding due to the demonstrated benefits of strength and power improvement for the function and quality of life of elderly people.

\section{CONCLUSIONS}

After 10 weeks of training with various conditioning programs for elderly women than 60 years, we observed that the program with an extra strength training session aimed at muscle mass gains resulted in greater improvements in strength in the arms and legs.

The multicomponent exercise programs supposed improvements in various hematological variables (HDL cholesterol, LDL cholesterol, baseline glucose and glycated hemoglobin).

The 4 week detraining period resulted in no significant changes in body composition, physical condition and hematological variables compared with post-training levels. Due to the changes observed after the extra strength training

\section{REFERENCES}

1. Häkkinen K, Kallinen M, Izquierdo M, Jokelainen K, Lassila H, Malkia E. Changes in agonist-antagonist EMG, muscle CSA, and force during strength training in middle-aged and older people. J Applied Physiol. (1998) 84:13419. doi: 10.1152/jappl.1998.84.4.1341

2. Grindler NM, Santoro NF. Menopause and exercise. Menopause. (2015) 22:1351-8. doi: 10.1097/GME.0000000000000536

3. Cadore E, Pinto R, Pinto S, Alberton C, Correa C, Tartaruga M, et al. Effects of strength, endurance, and concurrent training on aerobic power and dynamic neuromuscular economy in elderly men. J Strength Cond Res. (2011) 25:758-66. doi: 10.1519/JSC.0b013e318207ed66

4. Cadore E, Silveira R, Bottaro M, Izquierdo M. Strength and endurance training prescription in Healthy and Frail Elderly. Aging Dis. (2014) 5:18395. doi: 10.14336/AD.2014.0500183

5. Taguchi N, Higaki Y, Inoue S, Kimura H, Tanaka, K. Effects of a 12-month multicomponent exercise program on physical performance, daily physical activity, and quality of life in very elderly people with minor disabilities: an intervention study. J Epidemiol. (2010) 20:21-9. doi: 10.2188/jea.JE20081033

6. Toto PE, Raina KD, Holm MB, Schlenk EA, Rubinstein EN, Rogers JC. Outcomes of a multicomponent physical activity program for sedentary, community-dwelling older adults. J Aging Phys Act. (2012) 20:36378. doi: 10.1123/japa.20.3.363

7. Kang S, Hwang S, Klein AB, Kim SH. Multicomponent exercise for physical fitness of community-dwelling elderly women. J Phys Ther Sci. (2015) 27:9115. doi: 10.1589/jpts.27.911

8. Daly M, Vidt ME, Eggebeen JD, Simpson WG, Miller ME, Marsh AP, et al. Upper extremity muscle volumes and functional strength after resistance training in older adults. J Aging Phys Act. (2013) 21:186207. doi: 10.1123/japa.21.2.186

9. Delshad M, Ghanbarian A, Mehrabi Y, Sarvghadi F, Ebrahim, K. Effect of strength training and short-term detraining on muscle mass in women aged over 50 years old. Int J Prev Med. (2013) 4:1386-94.

10. Fragala M, Fukuda D, Stout J, Townsend J, Emerson N, Boone C, et al. Muscle quality index improves with resistance exercise training in older adults. Exp Gerontol. (2014) 53:1-6. doi: 10.1016/j.exger.2014. 01.027 session, in future studies, it would be beneficial to deepen the intensity, frequency, or to analyze the effects of a longer detraining period on this population.

\section{DATA AVAILABILITY STATEMENT}

The datasets generated for this study are available on request to the corresponding author.

\section{ETHICS STATEMENT}

The study was approved by the Clinical Research Ethics Committee of the University of Castilla-La Mancha and conducted in accordance with the Helsinki Declaration. The patients/participants provided their written informed consent to participate in this study.

\section{AUTHOR CONTRIBUTIONS}

RC-C, JG-R, TG-P, and DS-G conceptualized, designed and performed the experiments and analyzed and interpreted the data. RC-C, JG-R, TG-P, and DS-G edited and critically reviewed the manuscript. JG-R and DS-G wrote the manuscript.

11. Holsgaard-Larsen A, Caserotti P, Puggaard L, Aagaard P. Stair-ascent performance in elderly women: effect of explosive strength training. J Aging Phys Act. (2011) 19:117-36. doi: 10.1123/japa.19.2.117

12. Lovell D, Cuneo R, Gass G. The effect of strength and short-term detraining on maximum force and the rate of force development of older men. Eur J Appl Physiol. (2010) 109:429-35. doi: 10.1007/s00421-010-1375-0

13. Walker S, Häkkinen K. Similar increases in strength after short-term resistance training due to different neuromuscular adaptations in young and older men. J Strength Cond Res. (2014) 28:3041-8. doi: 10.1519/JSC.0000000000000381

14. Seco J, Abecia L, Echevarría E, Barbero I, Torres-Unda J, Rodríguez V, et al. A long term physical activity training program increases strength and flexibility, and improves balance in older adults. Rehabil Nurs. (2012) 38:3747. doi: $10.1002 / \mathrm{rnj} .64$

15. Rikli R, Jones, J. Development and validation of a functional fitness test for community-residing older adults. J Aging Phys Act. (1999) 7:129161. doi: 10.1123/japa.7.2.129

16. Bittner V, Weiner DH, Yusuf S, Rogers, WJ, McIntyre, et al. Prediction of mortality and morbidity with a 6-minute walk test in patients with left ventricular dysfunction. JAMA. (1993) 270:1702-7. doi: 10.1001/jama.1993.03510140062030

17. Guyatt GH, Sullivan MJ, Thompson PJ, Fallen EL, Pugsley SO, Taylor DW, et al. The 6-minute walk: a new measure of exercise capacity in patients with chronic heart failure. CMAJ. (1985) 132:919-23.

18. Myette-Côté É, Archambault-Therrien C, Brochu M, Dionne IJ, Riesco E. Physical fitness improvement in overweight postmenopausal women who do not lose fat mass in response to exercise training. Menopause. (2016) 23:1122-9. doi: 10.1097/GME.0000000000000677

19. Halverstadt A, Phares DA, Wilund KR, Goldberg AP, Hagberg JM. Endurance exercise training raises high-density lipoprotein cholesterol and lowers small low-density lipoprotein and very low-density lipoprotein independent of body fat phenotypes in older men and women. Metabolism. (2007) 56:44450. doi: 10.1016/j.metabol.2006.10.019

20. Amarante do Nascimento M, Gerage AM, Januário RS, Pina FL, Gobbo LA, Mayhew JL, et al. Resistance training with dietary intake maintenance increases strength without altering body composition in older women. J Sports Med Phys Fitness. (2018) 58:457-64. doi: 10.23736/S0022-4707.16.06730-X 
21. Ribeiro AS, Schoenfeld BJ, Souza MF, Tomeleri CM, Venturini D, Barbosa DS, et al. Traditional and pyramidal resistance training systems improve muscle quality and metabolic biomarkers in older women: a randomized crossover study. Exp Gerontol. (2016) 15:8-15. doi: 10.1016/j.exger.2016.03.007

22. Tomeleri CM, Ribeiro AS, Souza MF, Schiavoni D, Schoenfeld BJ, Venturini $\mathrm{D}$, et al. Resistance training improves inflammatory level, lipid and glycemic profiles in obese older women: a randomized controlled trial. Exp Gerontol. (2016) 84:80-7. doi: 10.1016/j.exger.2016.09.005

23. Martins RA, Veríssimo MT, Coelho e Silva MJ, Cumming SP, Teixeira AM. Effects of aerobic and strength-based training on metabolic health indicators in older adults. Lipids Health Dis. (2010) 9:76. doi: 10.1186/1476-511X-9-76

24. Raj I, Bird S, Westfold B, Shield A. Effects of eccentrically biased versus conventional weight training in older adults. Med Sci Sports Exerc. (2012) 44:1167-76. doi: 10.1249/MSS.0b013e3182442ecd

25. González-Ravé JM, Delgado $M$, Vaquero $M$, Juárez D, Newton RU. Changes in vertical jump height, anthropometric characteristics, and biochemical parameters after contrast training in master athletes and physically active older people. J Strength Cond Res. (2011) 25:1866-78. doi: 10.1519/JSC.0b013e318 $1 \mathrm{e} 4 \mathrm{f} 9 \mathrm{da}$
26. Jones CJ, Rikli RE, Beam WC. A 30-s chair-stand test as a measure of lower body strength in community-residing older adults. Res Q Exerc Sport. (1999) 70:113-9. doi: 10.1080/02701367.1999.10608028

27. American College of Sports Medicine. ACSM's Guidelines for Exercise Testing and Prescription. Philadelphia, PA: Lipincott Williams \& Wilkins (2014).

28. Hallage T, Krause MP, Haile L, Miculis CP, Nagle EF, Reis RS, et al. The effects of 12 weeks of step aerobics training on functional fitness of elderly women. $J$ Strength Cond Res. (2010) 24:2261-6. doi: 10.1519/JSC.0b013e3181ddacc6

Conflict of Interest: The authors declare that the research was conducted in the absence of any commercial or financial relationships that could be construed as a potential conflict of interest.

Copyright (c) 2020 González-Ravé, Cuéllar-Cañadilla, García-Pastor and Juárez Santos-García. This is an open-access article distributed under the terms of the Creative Commons Attribution License (CC BY). The use, distribution or reproduction in other forums is permitted, provided the original author(s) and the copyright owner(s) are credited and that the original publication in this journal is cited, in accordance with accepted academic practice. No use, distribution or reproduction is permitted which does not comply with these terms. 